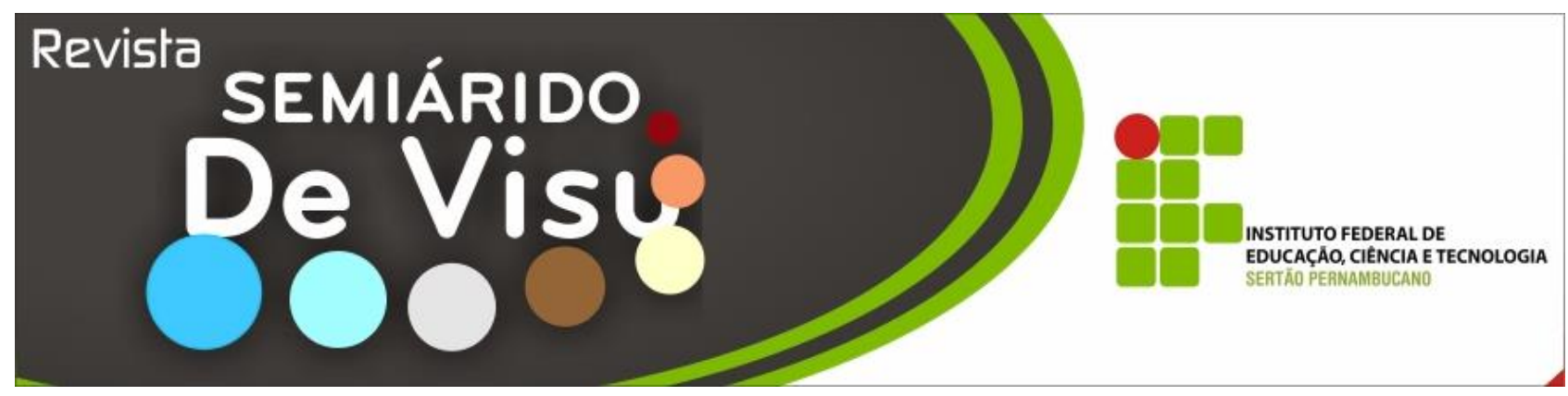

\title{
Sororreatividade para Brucella abortus e Brucella ovis em pequenos ruminantes no Sertão de Itaparica, PE
}

\author{
Maria de Fátima do Nascimento ${ }^{1}$, Maviael Lopes Ferraz ${ }^{2}$, Fabjane Samille da Silva ${ }^{3}$, Edilma \\ Zenilda de Souza ${ }^{4}$, Marileide de Souza Sá ${ }^{5}$, Mateus Matiuzzi da Costa ${ }^{6}$, \\ Rodolfo de Moraes Peixoto ${ }^{7}$
}
1,2,3,4,5,7 Instituto Federal de Educação, Ciência e Tecnologia do Sertão Pernambucano - IF Sertão-PE, Campus Floresta- PE. Rua Projetada, s/nº Caetano II, Floresta-PE, Brasil, CEP 56.400-000. Tel.: + 558738772708.
Email: ${ }^{1}$ marig.g12@hotmail.com; ${ }^{2}$ ferrazbranco@hotmail.com; ${ }^{3}$ bia_sousa16@hotmail.com;
${ }^{4}$ edilmazenilda@hotmail.com; ${ }^{5}$ marileide_florestana@hotmail.com; ${ }^{7}$ rmpeixoto.vet@gmail.com
${ }^{6}$ Universidade Federal do Vale do São Francisco - UNIVASF, Campus Ciências Agrárias, Rodovia BR 407, Km 12 - Lote 543 - Projeto de Irrigação Senador Nilo Coelho, s/nº, C1., Petrolina-PE, Brasil, CEP 56300-990/
Telefone + 5587 2101-8067/E-mail: ${ }^{6}$ mmatiuzzi@ hotmail.com

\begin{abstract}
RESUMO: Objetivou-se realizar um levantamento soro-epidemiológico da brucelose em pequenos ruminantes no sertão de Itaparica. Foram coletadas amostras de 239 caprinos e 435 ovinos, por meio de venopunção da jugular, sendo acondicionadas em caixa de isopor com gelo para envio ao laboratório. Para a pesquisa de anticorpos anti-Brucella abortus, utilizou-se o teste do antígeno acidificado tamponado (TAAT) e a técnica de fixação do complemento. Neste trabalho, todas as amostras de soro caprino analisadas $(\mathrm{n}=161)$ mostraram resultado negativo no TAAT. Com relação à espécie ovina, das 343 amostras submetidas ao TAAT, observou-se uma soropositividade de $0,87 \%$ ( $\mathrm{n}=03$ ), contudo, essas amostras foram negativas no teste de fixação do complemento. A infecção natural pela Brucella abortus não ocorre nos rebanhos de caprinos e ovinos avaliados neste trabalho. Registra-se a soropositividade para Brucella ovis na espécie ovina, porém em baixa freqüência. Dessa forma, salienta-se a importância da continuidade de estudos como esse no Estado de Pernambuco e em outros estados geograficamente próximos, devido a importância econômica que a doença apresenta.
\end{abstract}

Palavras-chave: brucelose, epidemiologia, diagnóstico, caprinos, ovinos.

\section{Seroreactivity to Brucella abortus and Brucella ovis in small ruminants in Sertão de Itaparica, PE}

\begin{abstract}
The objective was to conduct a survey sero-epidemiology of brucellosis in goats and sheep herds in the wilderness of Itaparica. Samples were collected from 239 goats and 435 sheep by jugular puncture and packed in box with ice for shipment to the laboratory. For detection of antibody anti-Brucella abortus, we used the test buffered acidified antigen (TAAT) and complement fixation technique. This work, all goat serum samples analyzed $(\mathrm{n}=161)$ showed a negative result in TAAT. With respect to sheep, from 343 samples submitted to TAAT, showed a seropositivity of $0.87 \%$ $(\mathrm{n}=03)$, however, these samples were negative complement fixation test. Natural infection by Brucella abortus does not occur in herds of goats and sheep in this work. This work is registered the seropositivity to Brucella ovis in sheep, but in low frequency. Thus, we highlight the continued importance of such studies in the state of Pernambuco and other states geographically close because of economic importance that the disease presents.
\end{abstract}

Keywords: brucellosis, epidemiology, diagnostic, goat, sheep. 


\section{Introdução}

A

brucelose é uma enfermidade infecto-contagiosa crônica que pode acometer diversas espécies animais. Trata-se de uma antropozoonose presente em todo o mundo, apresentando como etiologia bactérias intracelulares facultativas do gênero. No modo de transmissão, tem-se grande importância, alimentos ou água contaminados ingeridos pelo animal susceptível. A partir daí, a bactéria penetra na membrana mucosa e se instala no úbere, útero, testículos, baço ou linfonodos (SMITH, 1986). Pequenos ruminantes com a brucelose quase sempre abortam durante o terço final da prenhez (PADMORE, 1990). Os caprinos, e mais raramente os ovinos, podem manifestar sinais sistêmicos que incluem febre, apatia, perda de peso, diarréia, mastite, claudicação e orquite em machos (SMITH, 1986).

O animal infectado é a principal fonte de infecção para o homem e outros animais. $\mathrm{O}$ caráter zoonótico da doença acarreta perdas, na maioria das vezes relacionadas ao custo do tratamento humano e ao período de ausência no trabalho durante a convalescença (PAULIN e NETO, 2003). É classificada como uma doença ocupacional, já que o contato direto constitui risco de infecção. Outra forma de infecção é caracterizada pela ingestão de produtos contaminados. A difusão do agente ocorre, principalmente, por eliminação nas secreções vaginais e por meio do leite (POESTER et al., 2002). A comprovação do isolamento deste micro-organismo de amostras de leite cru proveniente de animais soropositivos para a brucelose aponta para a possibilidade da ocorrência da infecção em humanos por meio do consumo de leite e subprodutos in natura (LANGONI et al., 2000).

Estima-se que na América latina as perdas em decorrência da brucelose sejam da ordem de US\$ 25 milhões, acarretando uma série de problemas sociais e econômicos (MORENO, 2002). Esta doença em humanos pode evoluir para sintomas semelhantes ao da influenza, tais como febre, dores de cabeça, sudorese e indisposição, além de sintomatologia neurológica em virtude de possíveis inflamações no sistema nervoso central (SNC) (MADRUGA et al.,2001).

A brucelose em ovinos foi descrita inicialmente na Austrália e Nova Zelândia, no ano de 1953. É uma enfermidade que apresenta distribuição mundial, afetando rebanhos animais em vários estados do Brasil (LIRA e MEGID, 2009). A doença foi diagnosticada no Brasil pela primeira vez em 1966, no Rio Grande do Sul (RAMOS et al., 1966) e, em seguida, vários trabalhos de investigação foram publicados. De acordo com o Ministério da Agricultura, Pecuária e Abastecimento (MAPA) a brucelose causada pela Brucella melitensis é exótica no Brasil, desta forma, a infecção em caprinos ocorre por contato com a Brucella abortus.

Em caprinos, a brucelose caracteriza-se por abortamento, nascimento de crias fracas, mastite e lesões localizadas em vários tecidos (PADMORE, 1990). Nos ovinos, a ocorrência do aborto é rara, porém pode causar epididimite nos carneiros (PUGH, 2005). As pesquisas demonstram que a brucelose causada pela $B$. melitensis em caprinos é amplamente disseminada no Oriente Médio, Índia, Paquistão, África, México e alguns países da América do Sul (BRAUN, 1986; SMITH, 1986).

O diagnóstico da brucelose baseia-se no isolamento do agente em fetos abortados, placenta ou secreção vaginal. Além disso, existem alguns testes sorológicos disponíveis para identificação de animais positivos para infecção (SMITH \& SHERMAN, 1994). Os principais testes para o diagnóstico da brucelose são os que buscam detectar anticorpos no soro e leite. Dentre eles destacam-se como métodos indiretos a soroaglutinação lenta em tubos (SLT), teste do antígeno acidificado tamponado (TAAT), teste do 2-Mercaptoetanol (2-ME), reação de fixação do complemento (RFC), testes imunoenzimáticos (ELISA), teste da polarização da fluorescência (FPA), prova do anel em leite (PAL), sêmen plasma aglutinação (SPA) e imunodifusão em gel (IDG). Entretanto o Ministério da Agricultura, Pecuária e Abastecimento preconiza o teste do antígeno acidificado tamponado (TAAT) como prova de triagem, e como provas confirmatórias, o 2Mercaptoetanol (2-ME) e a Reação de Fixação 
do Complemento - RFC, para o diagnóstico da B. abortus (Brasil, 2003). Não existe tratamento para a doença, sendo realizado o controle da doença por meio da sorologia e sacrifício de animais soropositivos (BRASIL, 2004).

Tendo em vista a escassez de trabalhos sobre a ocorrência da infecção por B. abortus e a inexistência de estudos acerca da infecção por B.ovis e o seu impacto na economia do setor, justifica-se a realização de um estudo de diagnóstico da situação da brucelose nestes pequenos ruminantes na região de desenvolvimento do sertão de Itaparica.

\section{Material e métodos}

No estado de Pernambuco a região de desenvolvimento do sertão de Itaparica (RD Itaparica) tem sua economia caracterizada, entre outras atividades, pela exploração das áreas de sequeiro, sendo a caprinocultura um dos principais ramos da pecuária. A RD Itaparica compreende sete municípios (Belém do São Francisco, Carnaubeira da Penha, Floresta, Itacuruba, Jatobá, Tacaratu e Petrolândia) (Figura 1). Localizada no Semiárido nordestino, esta região sofre com uma série de adversidades climáticas, econômicas, sociais e ambientais, limitando suas potencialidades.
Com relação a caprino-ovinocultura, a RD Itaparica responde por $11,2 \%$ do rebanho ovino e $26,6 \%$ do rebanho caprino do estado, com destaque para o município de Floresta que detém o maior rebanho caprino do estado $(13,1 \%)$ (BRASIL, 2010).

Foram visitadas 16 propriedades de criação de caprinos e ovinos, localizadas nos municípios de Floresta e Itacuraba, dentro da mesorregião de desenvolvimento do sertão de Itaparica (RD Itaparica), utilizando-se as espécies caprina $(n=239)$ e ovina (435), totalizando 674 amostras. Foi realizada amostragem não-probabilística por conveniência de acordo com Thrusfield (2004).

Coleta de sangue

Após a contenção dos animais e antisepsia da veia jugular com álcool iodado, as amostras de sangue foram colhidas mediante venopunção da jugular, utilizando-se tubos vacutainer, obtendo-se um volume de aproximadamente $10 \mathrm{~mL}$ que permaneceu no tubo até completa retração do coágulo sanguíneo para a obtenção do soro. O material foi centrifugado $(5000 \mathrm{rpm} / 5 \mathrm{~min})$, sendo, então, estocado em microtubos e mantidos a $-20{ }^{\circ} \mathrm{C}$, até a realização dos exames sorológicos.

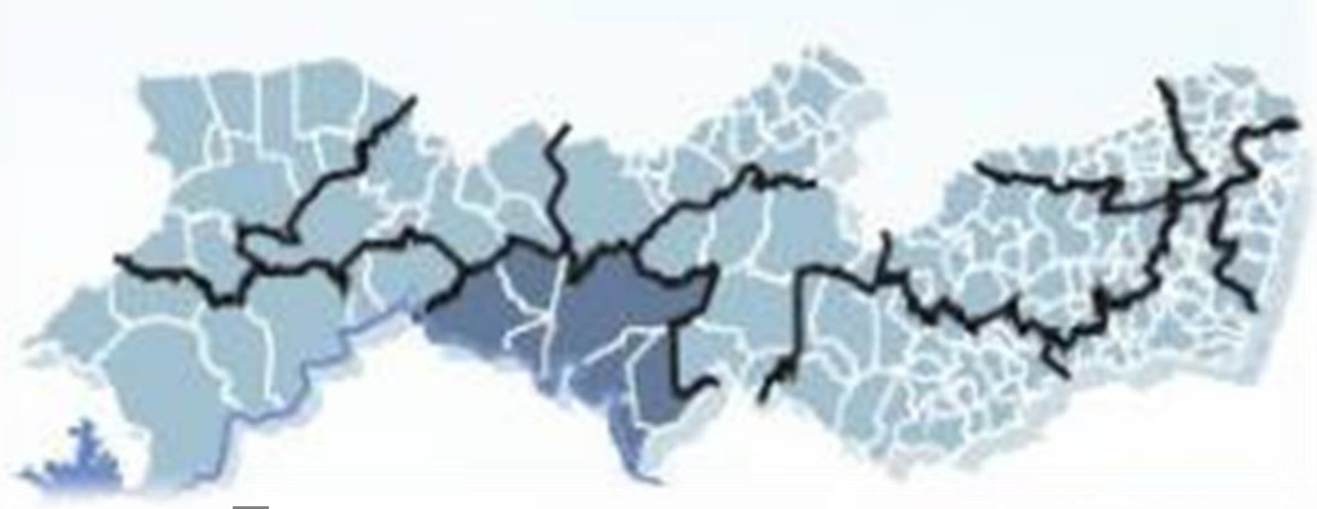

RD Sertão de Itaparica

Figura 1 - Mapa político demonstrando a delimitação da região de desenvolvimento do sertão de Itaparica no estado de Pernambuco. 
(NASCIMENTO et al., 2015)

Diagnóstico da brucelose

Foi empregada a Imunodifusão em Gel de Agarose (IDGA) para pesquisa de anticorpos anti-B. ovis. Para a pesquisa de anticorpos antiBrucella abortus foi utilizado o Teste do Antígeno Acidificado Tamponado (TAAT) em amostras de soro caprino e ovino, onde faz-se a deposição de $30 \mu \mathrm{L}$ de soro e $30 \mu \mathrm{L}$ de antígeno sobre uma placa de vidro.

O soro e o antígeno foram, então, misturados com movimentos circulares durante quatro minutos, quando foi realizada a leitura dos resultados em caixa de luz indireta. Os soros que apresentaram a presença de aglutinação foram considerados animais reagentes e aqueles com ausência de aglutinação, designados de animais não reagentes (BRASIL, 2003). As amostras dos animais reagentes no TAAT foram enviadas ao Laboratório Nacional Agropecuário (LANAGRO-PE), sendo submetidas ao teste de fixação do complemento.

\section{Resultados e discussão}

Nesse trabalho, todas as amostras de soro caprino analisadas $(\mathrm{n}=239)$, mostraram resultado negativo no TAAT (Tabela 1). Estes achados corroboram com os resultados relatados por Peixoto et al. (2008) que encontraram 100\% $(\mathrm{n}=222)$ de soronegatividade na pesquisa de anticorpos anti- B. abortus em caprinos criados na região do Submédio São Francisco. Em outro estudo realizado no sertão pernambucano, observou-se uma frequência de caprinos positivos para B. abortus de $0,6 \%$ (Pinheiro Junior et al, 2008). Estas semelhanças podem ser atribuídas as características dos sistemas de produção de caprinos encontrados nestas regiões, que empregam um modelo de criação predominantemente extensivo, diminuindo a probabilidade de transmissão de agentes infecciosos. Além disso, estes estudos foram desenvolvidos em regiões geograficamente próximas e com similaridades nos aspectos edafo-climáticos. Em estudo realizado no estado do Rio de Janeiro, encontrou-se uma soropositividade para a B. abortus de 5,6\% num rebanho caprino composto por 124 animais adultos (VARGES et al., 2008). Ainda, de acordo com estes autores, foi detectada uma fêmea bovina positiva para brucelose por meio do TAAT e do 2-ME em criação consorciada com os caprinos, reforçando o papel dos bovinos na cadeia epidemiológica da brucelose. $\mathrm{Na}$ Bahia, Carneiro et al. (2005) realizaram um inquérito sorológico por meio do TAAT e a prova de soroaglutinação lenta, sendo observada uma soropositividade para $B$. abortus em três caprinos. Estes autores ressaltam a necessidade de adoção medidas sanitárias adicionais à vacinação de fêmeas bovinas, como o tratamento de estercos e pasteurização do leite. Com relação à espécie ovina, das 435 amostras submetidas ao TAAT, observou-se uma soropositividade de $0,87 \%(\mathrm{n}=03)$. Entretanto, essas amostras foram negativas no teste de fixação do complemento, sendo indicativo de reação cruzada. Em um levantamento soroepidemiológico anti- $B$. abortus observou-se uma negatividade de $100 \%$ em amostras de ovinos criados no agreste pernambucano (Pinheiro Junior et al., 2005).

Tabela 1. Resultado do Teste do Antígeno Acidificado Tamponado e Fixação do Complemento em caprinos e ovinos criados na região do Sertão de Itaparica-PE, 2011.

\begin{tabular}{ccccc}
\hline \multirow{2}{*}{ Espécie } & \multicolumn{2}{c}{ TAAT } & \multicolumn{2}{c}{ Fixação do Complemento } \\
\cline { 2 - 5 } & Não Reagentes & Reagentes & Negativos & Positivos \\
\hline Caprina & 161 & - & - & - \\
Ovina & 340 & 03 & 03 & - \\
\hline
\end{tabular}

TAAT - Teste do Antígeno Acidificado Tamponado. 
Em outro trabalho, Pinheiro Junior et al. (2008) encontraram uma frequência de ovinos positivos para $B$. abortus de $2,5 \%$ no sertão pernambucano, resultado semelhante ao encontrado neste trabalho. Isto é reflexo das similaridades observadas nos estudos no que se refere às condições de manejo, número de animais avaliados e região estudada.

Na pesquisa de B. ovis, realizada em 238 amostras de soro ovino, obteve-se uma soroposividade de 1,06\% ( $\mathrm{n}=01$ ) (Tabela 2). Em estudo realizado no agreste de Pernambuco, Pinheiro Junior et al. (2005) observaram uma frequência de ovinos positivos para $B$. ovis de $4,76 \%$. Clementino et al. (2007) realizaram um inquérito soro-epidemiológico acerca dos fatores de risco associados à infecção por $B$. ovis em carneiros deslanados do Semiárido da Paraíba, sendo observada uma prevalência de $8,59 \%(\mathrm{n}=25)$ do total de propriedades visitadas (283). No estado de Alagoas, Pinheiro Junior et al. (2009) também encontraram a presença de ovinos positivos para $B$. ovis, sendo observado $3,1 \%$ de positividade de um total de 579 amostras analisadas. Silva et al. (2009) detectaram a presença da infecção por B. ovis em rebanhos comerciais de ovinos na Bahia, com um percentual de soropositividade de $3,27 \%$.

Nota-se que, em alguns trabalhos tem-se pouca variação no percentual de animais positivos. Isto pode ser atribuída à metodologia empregada, uma vez que a maioria dos estudos emprega o mesmo kit diagnóstico, além das condições de manejo e fatores climáticos.
A baixa soroprevalência encontrada pode ser em decorrência do pequeno número de animais dentro de cada rebanho avaliado, o que diminui a probabilidade de infecção (CLEMENTINO et al., 2007). Além disso, em trabalho realizado por Nascimento et al. (2012) na região do presente estudo, foi observado que $48,6 \%$ dos criadores de pequenos ruminantes não adquiriram machos nos últimos cinco anos e quando fazem a reposição, $37,1 \%$ tendem a comprar em propriedades vizinhas, dessa forma, com a baixa introdução de animais, tem-se menor probabilidade da introdução da B. ovis.

A implantação do Programa Nacional de Controle e Erradicação da Brucelose e Tuberculose (PNCEBT) contribuiu para a diminuição da prevalência da brucelose em bovinos nos últimos anos. Apesar disso, o problema não pode ser considerado solucionado. $\mathrm{O}$ combate à brucelose, com base apenas na vacinação de fêmeas bovinas com idade entre três e oito meses, permite uma diminuição das consequências nocivas, mas não a erradicação completa da doença. A Brucella spp. é um micro-organismo resistente às condições ambientais, podendo permanecer vivo por três a quatro meses em solo úmido, fezes, água parada e membranas fetais secas e fragmentadas.

Nascimento et al. (2012) realizou um estudo sobre o perfil sanitário das criações de ovinos e caprinos na mesma região em que o presente trabalho foi executado, sendo observado relatos por parte dos criadores da presença de abortos em pequenos ruminantes.

Tabela 2. Resultado do teste imunodifusão em gel de agarose para detecção de B. ovis em ovinos criados na região do Sertão de Itaparica-PE, 2011.

Imunodifusão em Gel de Agarose

Espécie

\begin{tabular}{lll}
\hline Positivo & Fraco Positivo
\end{tabular}

Ovina

01

22

215 
Alencar et al. (2010) realizaram um trabalho acerca do perfil sanitário dos rebanhos caprinos e ovinos no sertão de Pernambuco, sendo observado que os abortos foram relatados por $82,3 \%$ dos proprietários, além dos relatos acerca da presença de animais com secreções vaginais e demora na eliminação da placenta. Estes relatos são sugestivos da presença da brucelose, contudo são necessários estudos que permitam a detecção da Brucella spp. De maneira geral, tem-se observado que a brucelose em caprinos e ovinos não é amplamente estudada, sendo poucos os estudos de pesquisa no Brasil voltados para esta temática (CARNEIRO et al., 2005; CLEMENTINO et al., 2007; VARGES et al., 2008; PINHEIRO JUNIOR et al., 2008).

\section{Conclusões}

Registra-se a soropositividade para Brucella ovis, porém em baixa frequiência. A infecção natural pela Brucella abortus não foi observada nos rebanhos de caprinos e ovinos avaliados neste estudo desenvolvido na mesorregião do sertão de Itaparica. No entanto, salienta-se a importância da continuidade de estudos como esse no estado de Pernambuco e em outros estados geograficamente próximos, utilizando-se outras amostras, tais como o leite. Além disso, devem ser empregadas técnicas diagnósticas mais sensíveis, em virtude da importância econômica que esta enfermidade representa para o agronegócio da caprinoovinocultura.

\section{Referências bibliográficas}

ALENCAR, S.P.; MOTA, R.A.; COELHO, M.C.O.C.; NASCIMENTO, S.A.; ABREU, S.R.O.; CASTRO, R.S. Perfil sanitário dos rebanhos caprinos e ovinos no sertão de Pernambuco. Ciência Animal Brasileira, v.11, n.1, p.131-140, 2010.

BRASIL. Agência Estadual de Planejamento e Pesquisas de Pernambuco. Disponível na Internet:

http://www.portais.pe.gov.br/web/condepeFide m/itaparica, capturado em 22/02/2010, On line.
BRASIL. Programa Nacional de Controle e Erradicação da Brucelose e Tuberculose Bovina, 9p. Ministério da Agricultura e do Abastecimento, Departamento de Defesa Animal, 2003.

BRASIL. Programa Nacional de Controle e Erradicação da Brucelose e Tuberculose Bovina, Instrução Normativa SDA $\mathrm{N}^{\circ} 06$, de 08 de Janeiro de 2004.

BRAUN, W.F. Manifestations and aberrations of caprine pregnancy. Proceedings of Society for Theriogenology, 1986, Nashville, TN.

CARNEIRO, J.; ZACHARIAS, F.; PACHECO, S.T.; MENDONÇA-LIMA, F.W. Investigação da soropositividade para brucelose em rebanhos caprinos produtores de leite para consumo humano. Rev. Bras. Saúde Prod. An. v.6, n.2, p.53-58, 2005.

CLEMENTINO, I.J.; ALVES, C.J.; AZEVEDO, S.S.; PAULIN, L.M.; MEDEIROS, K.A. Inquérito soro-epidemiológico e fatores de risco associados à infecção por Brucella ovis em carneiros deslanados do semi-árido da Paraíba. Pesq. Vet. Bras., v.27, n.4, p.137-143, 2007.

LANGONI, H.; CHIHARA, S. M.; ILVA, A.V.; ARDO, R.B.; ONIN, F. B.; MENDONÇA, L.J. A.D. Isolation of Brucella ssp from milk of brucellosis positive cows in São Paulo and Minas Gerais states. Braz. J. vet. Res. Anim. Sci., v.37, n.6, p.444-448, 2000.

LIRA, N.S.C.; MEGID, J. Patogenia da brucelose ovina. Vet e Zootec, v.16, n.2, p.280289, 2009.

MADRUGA, C.R.; ARAÚJO, F.R.; SOARES, C.O. Imunodiagnóstico em medicina veterinária. Campo Grande: Embrapa, 2001, 360 p.

MORENO E . Brucellosis in Central America. Vet Microbiol.,v.90, n.1-4, p.31-38, 2002.

NASCIMENTO, M.F.; FERRAZ, M.L.; SÁ, M.S.; SILVA, S.L.; SOUZA, E.Z.; PEIXOTO, 
R.M. Perfil sanitário das criações de caprinos e ovinos na região de desenvolvimento do sertão de Itaparica, PE. In: VII Congresso Norte Nordeste de Pesquisa e Inovação, 7, 2012, Palmas. Anais. Palmas, TO, 2012.

PADMORE, C.L. Infections diseases of goats. Proceedings of the International Goat Producers Symposium, Tallahassee, FL, 1990, Florida A \& M University Press.

PAULIN, L.M.; NETO, J.S.F. O combate à brucelose bovina- situação brasileira. Jaboticabal:FUNEP, 2003, 154p.

PEIXOTO, R.M.; VESCHI, J.L.A.; NOGUEIRA, D.M.; KREWER, C.C.; COSTA, M.M. Inquérito soro-epidemiológico antiBrucella abortus em rebanhos caprinos na região Semiárida do Submédio São Francisco, PE. In: V Congresso Nordestino de Produção Animal, 5, 2008, Aracaju. Anais. Aracaju, SE, 2008.

PINHEIRO JUNIOR, J.W.; COLETO, Z.F.; LINO, G.C.; SILVA, L.B.G.; MOTA, R.A.; RABELO, S.S.A. Levantamento soroepidemiológico anti-Brucella abortus e B. ovis em rebanhos caprinos e ovinos no estado de Pernambuco. In: V Jornada de Ensino, Pesquisa e Extensão - XV Congresso de Iniciação Científica - JEPEX, 5, 2005, Recife. Anais. Recife: UFRPE, 2005.

PINHEIRO JUNIOR, J.W.; SOUZA, M.M.A.; GUERRA, N.R.; SANTANA, V.L.A.; MOTA, R.A. Frequência de aglutininas anti-Brucella abortus em caprinos e ovinos do sertão do estado de Pernambuco, Brasil. Ciência Animal Brasileira, v.9, n.4, p.1096-1101, 2008.

PINHEIRO JUNIOR, J.W.; OLIVEIRA, A.A.F.; MOTA, R.A.; AGOTTANI, J.V.; JESUS, E.M.; ASSIS, S.T.; OLIVEIRA, C.Z. Ocorrência de ovinos sororeatores para B. ovis no estado de Alagoas, Brasil. Vet e Zootec, v.16, n.3, p.500508, 2009.

POESTER, E.P.; GONÇALVES, V.S.; LAGE, A.P. Brucellosis in Brazil. Vet. Microbiol., v.90, n.1-4, p.55-62, 2002
PUGH, D. G. Clínica de ovinos e caprinos. $1^{\circ}$ ed. São Paulo: Roca, 2005, 513p.

RAMOS, A.A.; MIES FILHO, A.; SCHENCK, J.A.P.; VASCONCELLOS, L.D.; PRADO, O.T.G.; FERNANDES, J.C.T; BLOBEL, H. Epididimite ovina: levantamento clínico no Rio Grande do Sul. Pesq. Agropec. Bras., v.1, p.211-213, 1966.

SILVA, N.S.; BARROS, I.N.; DASSO, M.G.; ALMEIDA, M.G.Á.R.; LABORDA, S.S; ANUNCIAÇÃO, A.V.M.; MOREIRA, E.L.T.; LIMA-SILVA, A.E.; OLIVEIRA, E.M.D. Detecção de anticorpos anti-Brucella ovis em ovinos do estado da Bahia. Rev. Bras. Saúde Prod. An. v.10, n.4, p.852-859, 2009.

SMITH, M.C. Causes and diagnosis of abortion in goats. In Morrow DA, editor: Current therapy in theriogenology, $2^{\circ} \mathrm{Ed}$, Philadelphia, 1986, WB Saunders.

SMITH, M.C. e SHERMAN, D.M. Reproduction system. In SMITH, M.C. e SHERMAN, D.M. Goat Medicine, Philadelphia, 1994, Lea \& Febiger.

THRUSFIELD, M. V. Epidemiologia Veterinária. $2^{a}$ ed. São Paulo: ROCA, 2004, $556 \mathrm{p}$.

VARGES, R.; MEDEIROS, L.; LILENBAUM, W. Sororreatividade para Brucella abortus em rebanho caprino no estado do Rio de Janeiro, Brasil: relato de caso. R. Bras. Ci. Vet. v.15, n.2, p.103-104, 2008. 